\title{
Strategy Research of Standardization Construction of Intelligent City
}

\author{
Xiaoyan Liu ${ }^{1, a}$ \\ ${ }^{1}$ Nanyang Institute of Technology, Nanyang, China, 473004
}

Keywords: Intelligent City; Standardization Construction; Problem Analysis

\begin{abstract}
Smart city is based on strategic emerging technology, through a thorough and thorough perception, broadband flooding in the Internet, intelligent integration of the application and people-oriented continuous innovation, and ultimately the city's intelligent development. The establishment and perfection of the standardization system in the process of building the wisdom city is an important measure to solve the problems of urban resources and environment. Therefore, we should pay great attention to the construction of the intelligent city standardization. At present, the construction of intelligent city in our country is still in the early stage. It is the critical period of standardization construction. Therefore, it is important to study the potential standardization problem and determine the relevant standards as soon as possible. It can play an important guiding role in the design and construction, engineering implementation and management and maintenance of wisdom city and it can improve the technology and product interoperability, and ultimately achieve the wisdom of the city's sustainable development and large-scale development. The article analyzes the related problems of the standardization of the wisdom city, and puts forward the strategy of the standardization construction of the wisdom city.
\end{abstract}

\section{Introduction}

Intelligent city construction is a complex and systematic project, which not only involves the Internet of things technology, cloud computing technology, mobile communication technology, network information technology hardware technology, but also related to urban management, public services, public life and other software management theory, information system needs to face multiple external interfaces, the information sharing, the system of collaborative interaction requirements are high. The wisdom of urban construction standards is the wisdom of urban construction guidelines, under the guidance of various types of intelligent applications to achieve the unified planning and deployment, so as to achieve the wisdom of the city to lay a solid foundation for the industrialization of large-scale development.

\section{The Meaning of the Intelligent City}

Although the exploration and practice of wisdom city at home and abroad has been deepening, but for the wisdom of the city's connotation and definition has not yet reached a consensus, the author combined with domestic and foreign literature reports and experts and scholars of the research results, summed up the wisdom of the city as follows:

First of all, the construction of the wisdom city should take "people-oriented" as the core. With the deepening of socialist construction, the party and the country more and more emphasis on the happiness of people's lives index, the ultimate goal of national construction is to build a better life for the people, so the ultimate goal of intelligent city construction is to improve the convenience of residents living to improve the people's life happiness index, so its emphasis on "people-oriented." Second, achieve the sustainable development of the city. The essence of the wisdom of the city is a new development concept and way, and its ultimate goal is to achieve the sustainable development of the city. The background of the construction of intelligent city is to solve the urban population in the process of expansion of a series of population, resources, environmental problems, through the emerging technology to solve urban development issues, through the construction of intelligent city to promote the sustainable development of human society, the application of information 
technology flexible, accurate and rapid perception of urban development process related issues, improve the quality of life of urban residents, to achieve sustainable development of the city. Finally, the construction of the wisdom of the city is inseparable from the support of modern information technology. In the process of intelligent city construction, we need the advanced information technology to be flexible and accurate to understand and deal with the related problems in the process of urban development. It can be seen that information technology is a necessary condition for the operation of intelligent city. All the problems are solved by obtaining new information technology support for the premise. Thus, the wisdom of the city is a new type of urban development concept and model, which follow the "people-oriented" on the basis of the application of information technology to perceive the process of urban development process to deal with the various problems, and ultimately to improve the quality of life of urban residents to achieve the sustainable development of urban construction goals.

\section{The Composition of the Wisdom City Standard System}

As the wisdom of urban construction is still in its infancy, so at present in the country has not yet formed a unified construction standard system, also summed up the experience of experts and scholars and theoretical results, where the wisdom of urban construction standard system is divided into the overall standard, application of standards and safety standards:

The Overall Standard. The overall standard is the guidance of the wisdom of the city standard system, the overall standard, the other major technical units and application entities are based on the overall standard as the main content, including the wisdom of the city guide, wisdom city terminology, intelligent city overall structure and the overall Requirements, information and application system open requirements, assessment methods and guidance system. The wisdom city guidance includes the technical system, service system, evaluation index system and evaluation technology, key technology, spatial information service architecture, emergency response model and scheme, specific industry application and so on. Smart city terminology includes the basic terminology and definition of theory, technology, method, name in the field of intelligent city construction. The overall structure refers to the unified structure model of intelligent city planning and construction, which includes data acquisition layer, data activation layer, support service layer, application service layer and so on. City identification and analysis, including planning and construction process involved in the coding, symbols, patterns and other standards. Information and application system open technical requirements include information and system open principles, open objects, technical means. The evaluation method and index system of intelligent city mainly include first-level index, second-level index, three-level index and specific index system. Assessment methods include a variety of technologies, tools, system platforms and so on.

The Basic Standards. The basic standard is the basic communication technology standard, which is mainly used for information acquisition, transmission and processing. In addition to special standardization, the basic standards usually adopt the existing international standards, national standards and industry standards. In particular, the basic criteria include perceptual technical standards, wired and wireless communication technology standards, data storage and processing standards, basic software standards. Among them, the technical standards include sensor, image and audio and video acquisition standards, RFID standards, satellite navigation system standards. Wired and wireless communication technology is relatively mature, including wireless communications, IP and the Internet, cable access and transmission standards. Data storage and processing standards, including network storage standards and cloud computing standards, the current cloud computing standards are usually some white papers or technical reports, the majority has not yet formed a standard document. Basic software standards include system software standards, basic software middleware standards, etc. At present, Chinese software design to international standards.

The Application Standards. Application standards to industry-oriented, information and communication industry to participate in the development of public, platform standards, supplemented by specific application standards, including public support platform standards, the 
application of middleware standards, basic information system standards, industry application technology standards. Public support platform standards include requirements standards, architecture standards, interface standards, terminal equipment management protocols. Application middleware standard includes component middleware, database access middleware, data description middleware, embedded system based middleware, etc., can refer to the Internet of things application middleware related standards. The basic information system standard includes geospatial information system, population basic database, legal basis database, economic operation information database related technical standards, etc., to the city of the various clients to provide the necessary open interface and data services to achieve the use of information sharing and the largest The Industry applications and technical standards, which related to government, medical, transportation, food safety, intelligent community, cross-domain application standards and so on.

Safety Standards. The main role of the development of safety standards is to ensure the wisdom of urban construction in the network, information system security, including a variety of security technical standards, management standards, safety evaluation standards. The security technical standards include intelligent city security reference architecture, technical requirements, data encryption and decryption technology, security authentication technology, information security transmission technology, key technology, network identity management and information standards. Safety management standards include security level protection, security management system, management agencies, personnel management, operation and maintenance management. Security evaluation standards include network security evaluation standards and information security evaluation standards.

\section{The Standardization Construction Strategy of Wisdom Urban}

On the basis of analyzing the connotation of the wisdom city and the composition of the standard system, the author proposes to strengthen the standardization of wisdom city from the following aspects:

Learn From the Domestic and International Wisdom Urban Standardization Construction Experience. Chinese intelligent city standardization is still in the initial stage, so it is necessary to compare the domestic and international wisdom of urban standardization construction experience and results, and as a basis for standardization of scientific theory and practice system. On the one hand, it is necessary to analyze the strategic planning theory of smart city at home and abroad, clarify the importance of intelligent city construction and the interrelationship of various fields, including top-level design, government-led, public-private partnership mode and so on; to refine service standards, technical standards and industry standards. On the other hand, the analysis of the content and focus of intelligent city construction at home and abroad, learn from advanced experience, and promote the standardization and construction mode under the driving force of advantageous industries. The actual needs of the market and the public as the guide, based on reality, timely reporting, development, implementation of various standards to maximize the sharing of basic information resources to promote the development of intelligent application industry.

Build the Overall Framework of the Wisdom City Standard System and Improve the Top Design. In the process of standardization construction of intelligent city, the overall framework of the perfect standard system is the guidance and foundation of the construction. According to the content requirements of the intelligent city standard system, the overall framework of the standard system includes the service standard, the data standard, the application standard, the infrastructure Standards, management standards, security standards, etc., a variety of standards related to various industries, different business, in a unified standard system under the guidance of the overall framework, and then according to industry, business content corresponding to the standard sub-system to improve the entire top design architecture. In addition, the perfect top-level design can also open up the industry, the information barriers between departments. In the process of building a smart city different classification angle, different purposes, inevitably there will be information cross phenomenon, such as intelligent traffic and wisdom of the intersection of high-speed, intelligent community and wisdom of the intersection, etc., and will involve a number 
of industries, departments, so in the process of building a smart city to improve the top design can better coordinate the different sectors, clear the responsibilities and functions of various sectors, open up the information barriers.

Increase the Capital Investment and Personnel Training of the Wisdom City's Standardization. In the construction of the wisdom of the city need a lot of financial support, the construction of pilot cities, the relevant city management departments, government units, the financial sector to allocate a certain amount of money to support the standardization of intelligent city construction, encourage and support enterprises and institutions to participate in the wisdom of urban standards research and Formulate and clarify the standardization objectives and detailed tasks in the field, formulate the annual plan and development plan with high operability, and summarize the work summary of the standardization construction on a regular basis. In addition, to strengthen the wisdom of urban standardization construction of personnel training, gathering a number of intelligent city standardization construction of professionals to build a professional strong, comprehensive quality of the backbone of the talent team to promote the wisdom of urban standardization construction of the deepening.

\section{Conclusion}

In short, the standardization of intelligent city construction process is to promote the relevant departments of the unified understanding of the important basis for the development of orderly development, only to strengthen the wisdom of urban standardization in order to maximize the information exchange, resource sharing, improve the versatility of various standards, Construction and operating costs. Of course, the wisdom urban standardization is a long-term and complex strategic project and the future should be a phased, focused steady progress and strengthen the infrastructure, so as to effectively promote the wisdom of urban construction.

\section{Acknowledgements}

Fund Project: Research on Risk Early Warning and Guarantee Mechanism of Intelligent Urban Construction.

\section{References}

[1] Wu Yu Long, Ai Haojun. Smart city: the road of modern urban construction under the background of the Internet [M]. Electronic Industry Press, 2011: 22-25, 29-30.

[2] China Telecom Intelligent City Research Group. Wisdom City Road: scientific governance and urban personality [M]. Electronic Industry Press, 2011: 79-82.

[3] Li Feng, Ren Xuejia, Xing Liqiang, Liu Chun. Green wisdom city standardization development research [J]. China Economic and Trade Guide, 2014 (6): 4-13

[4] Su Wo, Feng Shigang. On the wisdom of the city standard system of hierarchical structure research [J]. China Management Information, 2014, 7 (17): 93-97

[5] Zhang Yonggang, Yue Gaofeng. Chinese smart city standard system research [J]. Standard Science, 2016 (11): 14-18

[6] Yan Ying. Research on the Status Quo and Countermeasures of Standardization Development of Internet of Things[J]. China Standardization .2016 (12): 82-85. 